\title{
Nomogram Model of LNR Predicts Survival in Premenopausal Patients with Node-positive Luminal Breast Cancer
}

\author{
TAO QIN ${ }^{1,2^{*}}$, YIN-DUO ZENG $^{2 *}$, QIANYI LU ${ }^{1 *}$, XINKE ZHANG $^{1}$, GE QIN $^{1}$, QIUFAN ZHENG ${ }^{1}$, \\ FEI XU ${ }^{1}$, ROUJUN PENG $^{1}$, ZHONGYU YUAN $^{1}$ and SHUSEN WANG ${ }^{1}$ \\ ${ }^{1}$ Department of Medical Oncology, Sun Yat-sen University Cancer Center, \\ The State Key Laboratory of Oncology in South China, \\ Collaborative Innovation Center for Cancer Medicine, Guangzhou, P.R. China; \\ ${ }^{2}$ Breast Tumor Center, Sun Yat-sen University Sun Yat-sen Memorial Hospital, Guangzhou, P.R. China
}

\begin{abstract}
Aim: The aim of this study was to assess the prognostic value of lymph node ratio $(L N R)$ in premenopausal patients with luminal breast carcinoma. Materials and Methods: A total of 885 female patients who presented with axillary lymph node-positive luminal breast cancer between 2000 and 2009 were investigated. Using X-tile, we classified patients into low-, intermediate- and high-risk groups based on LNR. The Kaplan-Meier method was used to determine cumulative survival curves. Cox proportional hazards analyses were used to identify the factors that contributed to diseasefree (DFS) and overall (OS) survival. Results: The median age of patients was 42 years (range $=21-58$ years). A training set of 295 patients and a validation set of 590 patients were used to determine the optimal LNR cut-off points (0.20 and 0.63). DFS was $87.7 \%, 77.4 \%$ and $53.9 \%(p<0.001)$ and $O S$ was $91.5 \%, 76.7 \%$ and $50.9 \%(p<0.0001)$ for the low- $(\leq 0.20)$, intermediate- (0.21-0.63) and high-risk (>0.63) groups, respectively. The 10-year DFS and OS rates were significantly longer in the low-risk group than in the high-risk group. Nomogram analysis demonstrated that LNR contributed more compared to nodal stage in predicting both DFS and OS. Conclusion: We conclude that LNR strongly predicts prognosis in premenopausal patients with lymph node-positive luminal breast cancer.
\end{abstract}

\footnotetext{
*These Authors contributed equally to this study.

Correspondence to: Professor Zhongyu Yuan, and Professor Shusen Wang, The State Key Laboratory of Oncology in South China, Collaborative Innovation Center for Cancer Medicine. No. 651 Dongfeng Road East, Sun Yat-Sen University Cancer Center, Guangzhou 510060, People's Republic of China. E-mail: yuanzhy@sysucc.org.cn and wangshs@sysucc.org.cn
}

Key Words: Lymph node ratio, breast cancer, luminal subtype, prognosis, nomogram.
Breast cancer is currently the leading cause of tumor-related deaths in China (1) and the second leading cause of tumorrelated deaths in females worldwide (2). Multidisciplinary approaches that include surgery, chemotherapy, radiotherapy and endocrine therapy are effective in reducing tumor recurrence and cancer-related death in selected patients. However, such patients have markedly different survival outcomes given the heterogeneity observed in their molecular expression profiles $(3,4)$. Age, which is closely associated with menopausal status, has been shown in analyses of large sample databases to be an important factor correlated with prognosis $(5,6)$. In addition, the proportion of patients with luminal A-like subtype has gradually declined and that of those with luminal B-like human epidermal growth factor receptor-2 (HER2-negative) disease has increased (7). Therefore, various studies have attempted to identify molecular biomarkers that can be used to predict breast cancer recurrence, and numerous promising biomarkers have been evaluated as potential prognostic predictors of breast cancer.

Endocrine therapy is a primary component of treatment regimens aimed at managing estrogen receptor (ER)-positive or progesterone receptor $(\mathrm{PR})$-positive breast cancer $(8,9)$. The Early Breast Cancer Trialists' Collaborative Group metaanalysis of 2000 demonstrated that women with hormone receptor-positive breast cancer had a $50 \%$ reduction in the annual rate of recurrence and a $31 \%$ reduction in breast cancer-related mortality after 5 years of adjuvant tamoxifen treatment (10). Currently, the standard endocrine therapy used to treat premenopausal women is a selective ER modulator, such as tamoxifen $(11,12)$. Recently, two phase III studies both indicated that the addition of ovarian function-suppressing drugs significantly improves diseasefree survival (DFS) $(13,14)$. In addition, other trials have confirmed that 10 years of treatment with tamoxifen was more effective than 5 years of treatment with tamoxifen in 
treating early breast cancer (15). Few studies have examined which patients most benefit from longer-term tamoxifen treatment; hence, this evidence should be further explored to distinguish its effects on patients with luminal breast cancer.

Recurrence patterns are different among patients with luminal, HER2-enriched or triple-negative breast cancer (16). Recurrence tests, such as Adjuvant! Online and Oncotype DX, can be used to determine an individual's risk of developing recurrent cancer (17). The St. Gallen consensus, conducted from 2009 to 2013, suggested that age, tumor size, lymph node stage, ER/PR status, HER2 expression and molecular subtype were prognostic factors in early-stage breast cancer $(18,19)$. Recently, the results of several prognostic models for breast cancer were compared, including the Breast Cancer Index, Oncotype DX recurrence scores (20), IHC4 scores (21) and the HOXB13/IL17BR $(\mathrm{H} / \mathrm{I})$ index $(22)$, to produce a model that can predict the risk of disease recurrence. In addition, a study from the CALGB9741 trial that used body mass index (BMI) and PAM50 analyses determined that baseline BMI and molecular subtype affected patient prognosis (23). Given the biological heterogeneity of cancer, the present staging system, even when used in combination with molecular subtype information, remains inadequate in predicting breast cancer prognosis. Therefore, we hypothesized that additional biomarkers could complement nodal staging. These additional biomarkers could be used in combined sets to improve the prognostic stratification of patients with breast cancer.

Lymph node ratio (LNR) is considered an attractive potential biomarker that complements TNM classification in breast cancer. In addition, the LNR has been reported in breast cancer and identified as an important factor in many different types of cancer, such as head and neck cancer, esophageal cancer, melanoma, oral cavity squamous cell carcinoma and non-small cell lung cancer (24-28). The LNR plays an important role in predicting locoregional recurrence, early distant metastasis and it can function as an alternative to $\mathrm{pN}$ staging in lymph node-positive breast cancer (29-31). However, patients presenting with different molecular subtypes and stages may benefit from different treatment strategies. A commercial panel of 21 genes was used to distinguish genotypes with a favorable prognosis from those with an unfavorable prognosis in luminal-A subtype patients, as recommended by the National Comprehensive Cancer Network (NCCN) guidelines (32). Scores on this panel were shown to affect the decisions that physicians made regarding patient treatment options (33). However, this panel is unavailable in many countries and it is expensive $(34,35)$. Therefore, the present study compared prognoses in patients with different LNRs and stage II premenopausal luminal breast cancer to provide information that might be useful in personalized therapies.

\section{Materials and Methods}

This retrospective analysis included patients with histologically proven unilateral invasive ductal breast cancer who were treated between January 2000 and December 2009 at Sun Yat-Sen University Cancer Center. No tissues, blood samples or private information was obtained from patients in this study. Therefore, this study was not required to be approved by the Ethics Committee of Sun Yat-Sen University Cancer Center.

All patients were staged according to the American Joint Committee on Cancer (AJCC 2010, seventh edition) TNM Staging System for Breast Cancer (36) evaluation was performed prior to neo-adjuvant therapy or surgery, depending on which procedure came first. Patients with distant metastases at the initial diagnosis who were also node-negative were excluded. The following information was collected, assessed and retrospectively reviewed: demographic features; tumor characteristics (pathological subtype, size, grade, lymphovascular invasion, hormone receptor status, and HER2 expression); treatment protocols (surgery, adjuvant chemotherapy, radiotherapy, hormonal therapy, and trastuzumab) and clinical outcomes.

We selected women with primary breast cancer who underwent axillary lymph node dissection. For each of these women, the total number of nodes examined was noted in the pathology report, and they were found to have presented with one or more involved (i.e. positive) lymph nodes. In addition, the selected patients were required to have the following criteria: undergone mastectomy, breast-conserving surgical treatment, or treatment with an adjuvantselective ER modulator after chemotherapy and radiotherapy (if indicated); a known tumor size and premenopausal status, which was defined as regularly occurring menses or plasma folliclestimulating hormone and estradiol level not in the postmenopausal range at diagnosis. Chemotherapy regimens were performed as recommended by NCCN guidelines for adjuvant chemotherapy.

Patients were excluded if they were peri-menopausal, which was defined as older than 45 years with a decrease in ovarian estrogen synthesis and chemotherapy-related amenorrhea, or postmenopausal and presented with the following: hormone receptor-negative breast cancer; evidence of metastasis or cancer in the contralateral breast; a prior history of malignancy including breast cancer; nodenegativity; or pathologically confirmed in situ ductal carcinoma or in situ lobular carcinoma, or inflammatory breast cancer. Patients were also excluded if their medical records did not include the total number of nodes, only contained sentinel node information, or were incomplete and lacking information such as hormone receptor status and follow-up assessments. Tumor grades and histological classifications were based on WHO criteria (37). The ER and PR status of the primary tumor were determined using immunohistochemistry, and staining of $>10 \%$ of cells was defined as positive. Patients were considered HER2-positive if HER2 protein expression measured $3+$ intensity when examined using immunohistochemistry or they head amplification of the HER2/neu gene using fluorescence in situ hybridization.

A total of 885 female patients diagnosed with invasive breast carcinoma were included in the study. A flow chart describing the selection process is shown in Figure 1. The follow-up schedule was every 3-4 months within the first 3 years of treatment and 4-6 months after that if adjuvant endocrine therapy was regularly prescribed. All patients regardless of DFS events were followed-up until 31 Aug 2014 via out-patients clinic or via telephone. 


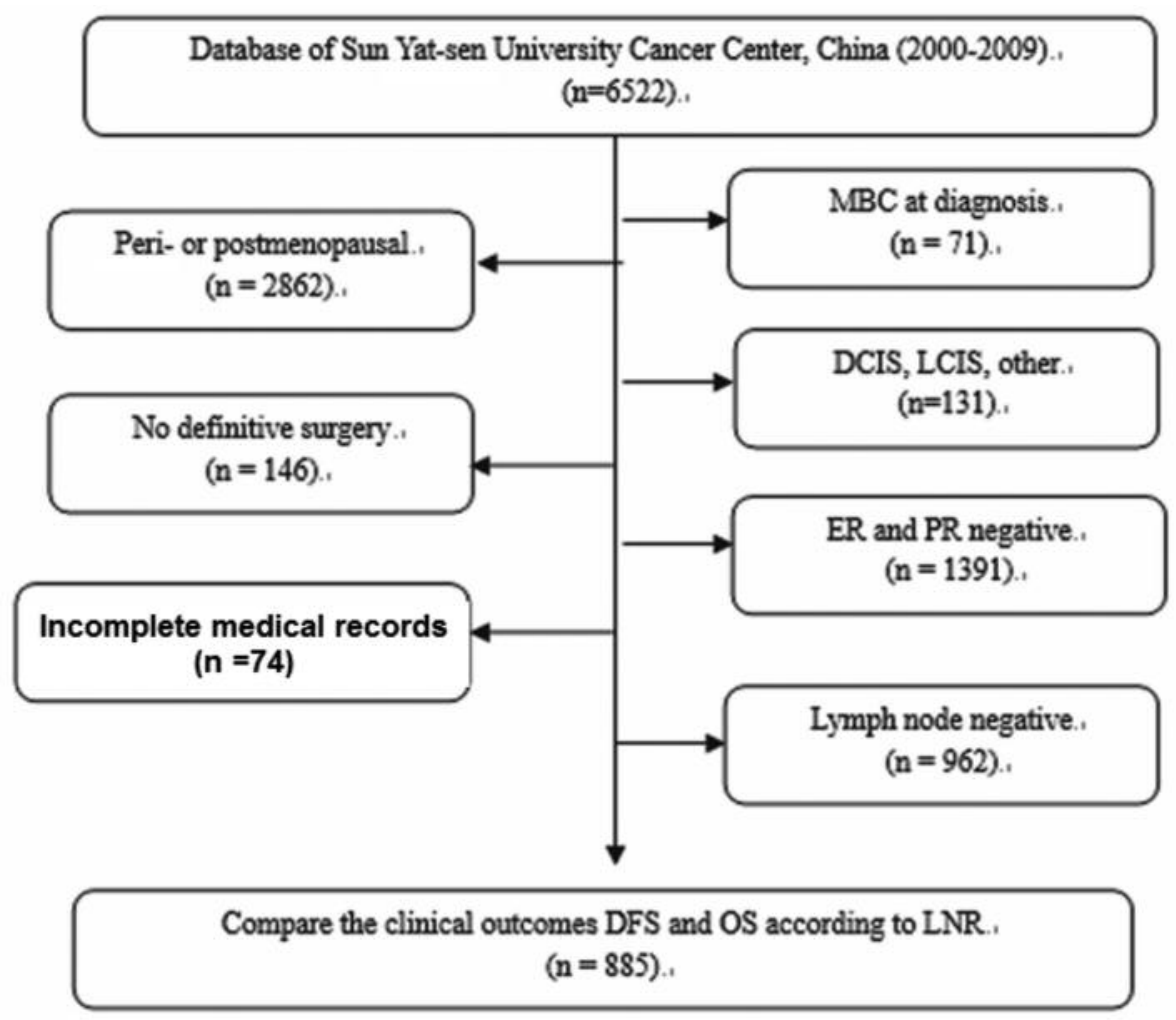

Figure 1. Patient enrollment flow chart. MBC: Metastatic breast cancer; DCIS: ductal carcinoma in situ; LCIS: lobular carcinoma in situ; ER: estrogen receptor; PR: progesterone receptor; DFS: disease-free survival; OS: overall survival; LNR: lymph node ratio.

Statistical analysis. Descriptive analyses were performed for demographic and clinical patient characteristics. The cut-off LNR value was determined using X-tile software (38). DFS was defined as the time from surgery to locoregional recurrence, distant metastasis, or death from any cause. Overall survival (OS) was defined as the time from surgery to death from any causes. KaplanMeier analysis was performed to examine the influence of predefined factors on survival, and log-rank tests were used to compare strata. Cox regression analysis was used to conduct a multivariate analysis of factors associated with OS or DFS. The first endpoint was DFS, and the second endpoint was OS. The statistical analysis was performed using SPSS software version 19.0 (IBM Corp., Armonk, NY, USA), MedCalcsoftware version 12.7 (MedCalc Software,Ostend, Belgium) and R software version 3.2.2 (The R Foundation for Statistical Computing, Vanderbilt University, Nashville, TN). Statistical significance was set at a value of $p<0.05$.

\section{Results}

Characteristics of patients with luminal breast cancer. The median follow-up duration was 92.98 months (range=6.93 to 176.16 months). A total of 885 female patients with breast cancer were enrolled in the study, with a median age of 42 years (range $=21$ to 58 years). A large majority of the patients $(87 \%)$ had at least 10 or more lymph nodes removed. The mean tumor size was $3.30 \mathrm{~cm}$ (range $=1.0$ to $11.0 \mathrm{~cm}$ ). The median positive number of lymph nodes and the total number of dissected axillary lymph nodes were 3.329 (range 1 to 51) and 16.198 (range 1 to 63), respectively. In addition, HER2 expression was positive in 180 of the tumors. Fifty-five patients who received neo-adjuvant chemotherapy were also included in this study. All of the patients included in the study received radiotherapy, chemotherapy, or hormone therapy either alone or in combination. The clinicopathological characteristics of the patients are shown in Table I.

Determining the cut-off point for LNR and its association with prognosis. In the first stage of multivariate analyses, clinical prognostic factors containing patient age at diagnosis, tumor size, grade, nodal stage, TNM stage, ER status, PR status, HER2 status, Ki67 index and LNR were included. The results indicated LNR was an independent prognostic factor for DFS (Table II).

Next, X-tile software was used to determine the lower and upper LNR values in these patients. X-Tile divided the cohort at a 1:2 ratio into two independent data sets, a test set and a validation set, determined the optimal cut-off points for LNR for the test set, and applied this value to the 
validation set. The results, shown in Figure 2 as distribution histograms, demonstrate a sharply defined lower LNR cutoff point of 0.20 and an upper LNR cut-off point of 0.63 . Thereafter, we used this pair of cut-off points to classify patients with an LNR $<0.20$ as low risk, with an LNR between 0.21 and 0.63 as intermediate risk, and an LNR greater than 0.63 as high risk in predicting breast cancer recurrence. According to two cut-off points, the number of patients overlapping between LNR and pN3, pN2, pN1 in high-risk, intermediate-risk and low-risk groups were 109, 196 and 407, respectively (Figure 3).

For the whole patient cohort, univariate Kaplan-Meier survival estimates of DFS and OS were determined according to risk groups that were defined using upper and lower values of LNR of 0.20 and 0.63 (Figure 4A and B). We also determined Kaplan-Meier survival estimates for DFS and OS according to the risk groups that were defined by the LNR cutoff values of 0.20 and 0.65 (39). The results showed that patients in the high-risk group had significantly worse DFS and OS than patients in the other two groups (Figure 4C and D). The 10-year DFS rate for patients in the low-, intermediate-, and high-risk LNR groups were $87.7 \%, 77.4 \%$, and $53.9 \%$, respectively (log-rank chi-squared $=84.032, p<0.001)$. The $10-$ year OS rates for patients in the low-, intermediate-, and highrisk LNR groups were $91.5 \%, 76.7 \%$, and $50.9 \%$, respectively $(\log$-rank chi-squared $=121.043, p<0.001)$.

LNR in predicting DFS and OS. Univariate analyses indicated that $\mathrm{pN}$ staging was significantly able to predict DFS (Tables II and III). Moreover, univariate analyses also showed that LNR was a significant factor for both DFS and OS (Tables II and III). Furthermore, in order to compare the accuracy of LNR to that achieved using $\mathrm{pN}$ staging in predicting DFS and OS, we confirmed that the area under the curve (AUC) for LNR was larger than that for $\mathrm{pN}$ staging (Figure 5A).

Multivariate analyses showed that patient age at diagnosis, tumor size, grade, nodal stage, TNM stage, ER status, HER2 status, Ki67 index and LNR were independent factors for DFS (Table II). In addition, we performed multivariate analyses of OS in which patient age at diagnosis, tumor grade, Ki67 index and LNR were also independent prognostic factors for OS (Table III). The above results indicate that LNR may predict DFS and OS.

Nomogram analysis included the factors age, tumor size, grade, nodal stage, TNM stage, ER status, PR status, HER2 status, Ki67 index and LNR. The results showed that LNR was the greatest contributor in predicting both DFS and OS (Figure 6).

\section{Discussion}

In this study, we demonstrated that patients in high- and intermediate-risk groups were at significantly higher risk for
Table I. Characteristics of the 885 patients with breast cancer

\begin{tabular}{|c|c|c|}
\hline Characteristic & $\mathrm{N}$ & $\%$ \\
\hline Median age, years & \multicolumn{2}{|c|}{$42(21-58)$} \\
\hline$<30$ & 50 & 5.6 \\
\hline $30-40$ & 358 & 40.5 \\
\hline $40-50$ & 434 & 49.0 \\
\hline$>50$ & 43 & 4.9 \\
\hline \multicolumn{3}{|l|}{ Tumor size, $\mathrm{cm}$} \\
\hline Median (range) & \multicolumn{2}{|c|}{$3.30(1.0-11.0)$} \\
\hline$\leq 2.0$ & 221 & 25.0 \\
\hline$>2.0$ & 664 & 75.0 \\
\hline \multicolumn{3}{|c|}{ No. of lymph nodes removed } \\
\hline Mean (range) & \multicolumn{2}{|c|}{$16.18(1-63)$} \\
\hline $1-3$ & 8 & 0.9 \\
\hline $4-6$ & 37 & 4.2 \\
\hline $7-9$ & 70 & 7.9 \\
\hline$\geq 10$ & 770 & 87.0 \\
\hline \multicolumn{3}{|l|}{ Histological grade } \\
\hline I & 137 & 15.4 \\
\hline II & 296 & 33.5 \\
\hline III & 452 & 51.1 \\
\hline \multicolumn{3}{|c|}{ No. positive lymph nodes } \\
\hline Mean (range) & \multicolumn{2}{|c|}{$5.29(1-51)$} \\
\hline $1-3$ & 481 & 54.4 \\
\hline $4-9$ & 252 & 28.5 \\
\hline$\geq 10$ & 152 & 17.2 \\
\hline \multicolumn{3}{|l|}{ LNR } \\
\hline Mean (range) & \multicolumn{2}{|c|}{$0.33(0.2-1.0)$} \\
\hline$<0.20$ & 427 & 48.2 \\
\hline $0.21 \leq x<0.63$ & 307 & 34.7 \\
\hline$>0.63$ & 151 & 17.1 \\
\hline \multicolumn{3}{|l|}{ TNM stage } \\
\hline II & 454 & 51.3 \\
\hline III & 431 & 48.7 \\
\hline \multicolumn{3}{|l|}{ ER } \\
\hline Positive & 743 & 84.0 \\
\hline Negative & 142 & 16.0 \\
\hline \multicolumn{3}{|l|}{ PR } \\
\hline Positive & 821 & 92.8 \\
\hline Negative & 64 & 7.2 \\
\hline \multicolumn{3}{|l|}{ HER2 } \\
\hline Negative & 705 & 79.7 \\
\hline Positive & 180 & 20.3 \\
\hline \multicolumn{3}{|l|}{ Ki67 index } \\
\hline$\leq 14 \%$ & 379 & 42.8 \\
\hline$>14 \%$ & 394 & 44.5 \\
\hline Unknown & 112 & 12.7 \\
\hline \multicolumn{3}{|c|}{ Neo-adjuvant chemotherapy } \\
\hline No & 768 & 86.8 \\
\hline Yes & 117 & 13.2 \\
\hline \multicolumn{3}{|l|}{ Surgery } \\
\hline Mastectomy & 845 & 95.5 \\
\hline Lumpectomy & 40 & 4.5 \\
\hline Chemotherapy & & \\
\hline No & 20 & 2.3 \\
\hline Yes & 865 & 97.7 \\
\hline Radiotherapy & & \\
\hline Yes & 462 & 52.2 \\
\hline No & 423 & 47.8 \\
\hline Endocrine therapy & & \\
\hline Tamoxifen & 701 & 79.2 \\
\hline Toremifene & 184 & 20.8 \\
\hline
\end{tabular}

ER, Estrogen receptor; PR, progesterone receptor; HER2, human epithelial receptor 2; LNR, lymph node ratio. 
Table II. Univariate and multivariate analyses of disease-free survival.

\begin{tabular}{|c|c|c|c|c|c|c|c|c|}
\hline \multirow{3}{*}{ Variable } & \multicolumn{4}{|c|}{ Univariate } & \multicolumn{4}{|c|}{ Multivariate } \\
\hline & \multirow[t]{2}{*}{ HR } & \multicolumn{2}{|c|}{$95.0 \% \mathrm{CI}$} & \multirow[b]{2}{*}{$p$-Value } & \multirow[b]{2}{*}{$\mathrm{HR}$} & \multicolumn{2}{|c|}{$95.0 \% \mathrm{CI}$} & \multirow[b]{2}{*}{$p$-Value } \\
\hline & & Lower & Upper & & & Lower & Upper & \\
\hline Age (continuous) & 0.954 & 0.932 & 0.976 & $<0.001$ & 0.957 & 0.935 & 0.980 & $<0.001$ \\
\hline Tumor size (continuous) & 1.016 & 1.008 & 1.025 & $<0.001$ & 1.008 & 0.999 & 1.018 & 0.086 \\
\hline Grade (III vs. I-II) & 2.676 & 2.045 & 3.743 & $<0.001$ & 2.423 & 1.788 & 3.283 & $<0.001$ \\
\hline Nodal stage (N2-3 vs. N1) & 1.714 & 1.416 & 2.074 & $<0.001$ & 0.894 & 0.601 & 1.331 & 0.582 \\
\hline Stage (III vs. II) & 1.957 & 1.422 & 2.694 & $<0.001$ & 0.917 & 0.505 & 1.665 & 0.776 \\
\hline ER (positive vs. negative) & 0.586 & 0.406 & 0.847 & 0.004 & 0.596 & 0.406 & 0.874 & 0.008 \\
\hline PR (positive $v s$. negative) & 0.786 & 0.454 & 1.360 & 0.389 & 0.811 & 0.461 & 1.427 & 0.467 \\
\hline HER2 (positive $v s$. negative) & 1.505 & 1.128 & 2.007 & 0.005 & 1.641 & 1.157 & 2.328 & 0.005 \\
\hline Ki67 (>14\% vs. $\leq 14 \%)$ & 1.914 & 1.548 & 2.366 & $<0.001$ & 1.338 & 1.065 & 1.681 & 0.012 \\
\hline LNR (continuous) & 7.704 & 4.723 & 12.567 & $<0.001$ & 8.355 & 4.042 & 17.269 & $<0.001$ \\
\hline
\end{tabular}

ER, Estrogen receptor; PR, progesterone receptor; HER2, human epithelial receptor 2; LNR, lymph node ratio; HR: hazard ratio; CI: confidence interval.

Table III. Univariate and multivariate analyses of overall survival.

\begin{tabular}{|c|c|c|c|c|c|c|c|c|}
\hline \multirow{3}{*}{ Variable } & \multicolumn{4}{|c|}{ Univariate } & \multicolumn{4}{|c|}{ Multivariate } \\
\hline & \multirow[t]{2}{*}{ HR } & \multicolumn{2}{|c|}{$95.0 \% \mathrm{CI}$} & \multirow[b]{2}{*}{$p$-Value } & \multirow[b]{2}{*}{ HR } & \multicolumn{2}{|c|}{$95.0 \% \mathrm{CI}$} & \multirow[b]{2}{*}{$p$-Value } \\
\hline & & Lower & Upper & & & Lower & Upper & \\
\hline Age (continuous) & 0.964 & 0.942 & 0.987 & 0.002 & 0.973 & 0.951 & 0.996 & 0.019 \\
\hline Tumor size (continuous) & 1.029 & 1.022 & 1.036 & $<0.001$ & 1.006 & 0.997 & 1.015 & 0.199 \\
\hline Grade (III vs. I-II) & 2.247 & 1.685 & 2.995 & $<0.001$ & 1.855 & 1.390 & 2.477 & $<0.001$ \\
\hline Nodal stage (N2-3 vs. N1) & 2.348 & 1.941 & 2.841 & $<0.001$ & 1.280 & 0.863 & 1.899 & 0.220 \\
\hline Stage (III $v s$. II) & 3.371 & 2.370 & 4.796 & $<0.001$ & 1.206 & 0.657 & 2.215 & 0.546 \\
\hline ER (positive $v s$. negative) & 0.922 & 0.613 & 1.386 & 0.696 & 1.097 & 0.719 & 1.673 & 0.667 \\
\hline PR (positive $v s$. negative) & 0.774 & 0.447 & 1.340 & 0.361 & 0.885 & 0.506 & 1.550 & 0.670 \\
\hline HER2 (positive $v s$. negative) & 1.214 & 0.843 & 1.747 & 0.298 & 1.123 & 0.773 & 1.631 & 0.542 \\
\hline Ki67 (>14\% vs. $\leq 14 \%)$ & 1.864 & 1.506 & 2.307 & $<0.001$ & 1.386 & 1.093 & 1.758 & 0.007 \\
\hline LNR (continuous) & 10.809 & 6.661 & 17.541 & $<0.001$ & 4.438 & 2.018 & 9.760 & $<0.001$ \\
\hline
\end{tabular}

ER, Estrogen receptor; PR, progesterone receptor; HER2, human epithelial receptor 2; LNR, lymph node ratio; HR: hazard ratio; CI: confidence interval.

breast cancer recurrence than the patients in the low-risk group. The 10-year survival rate in the low-risk group was significantly higher than the rates in patients in the intermediate-risk and high-risk groups. We determined that LNR was the most important prognostic factor for both disease recurrence and mortality in premenopausal patients with node-positive luminal breast cancer.

Approximately $70 \%$ of human breast tumors express hormone receptors, such as the ER and PR. These receptors are the primary transcription factors that drive oncogenesis in hormone receptor-positive breast cancer (40). By contrast, invasive lobular carcinoma (ILC) represents the second most common breast cancer histological subtype, accounting for 10$15 \%$ of all breast cancer, and the vast majority of these tumors express hormone receptors (41). ILC differs from invasive ductal carcinomas in its epidemiology, clinicopathological features, and natural history, based on varied molecular subtypes (42). Histological classification is important for selecting drugs to treat hormone receptor-positive breast cancer. Therefore, we selected invasive ductal breast cancer for this study to avoid potential biases from other types of breast cancer. In this study, we found that $84 \%$ of patients were ER-positive and that more than $90 \%$ of patients were PR-positive. 

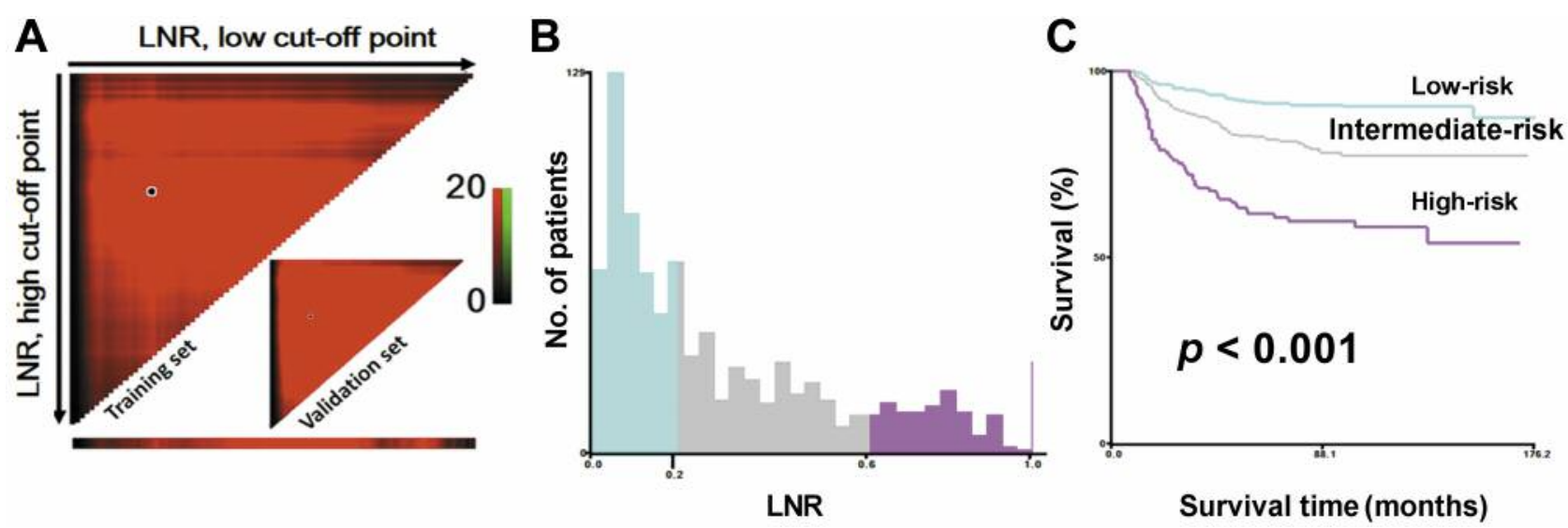

Figure 2.X-Tile analysis was conducted on patient from our database, assigned 1:2 into training and validation sets. A: Training sets and matched validation sets; $B$ : histogram of the entire cohort; C: Kaplan-Meier plot compared among three risk groups. Lymph node ratio (LNR) was divided at the optimal cut-point, as defined by the most significant (brightest) pixel on the plot $(0.20$ and $0.63, p<0.0001)$.

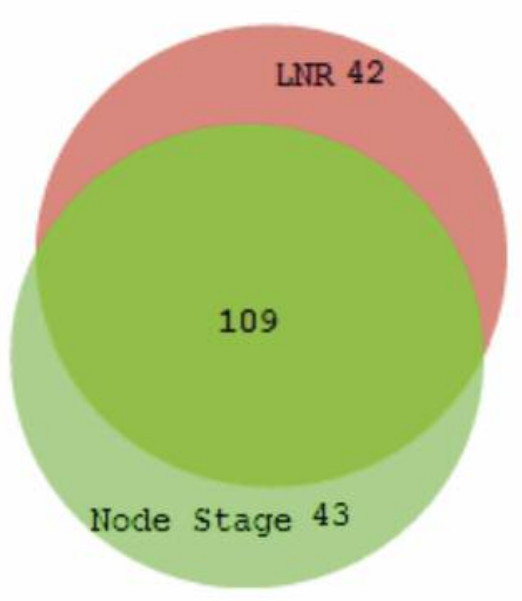

High-risk

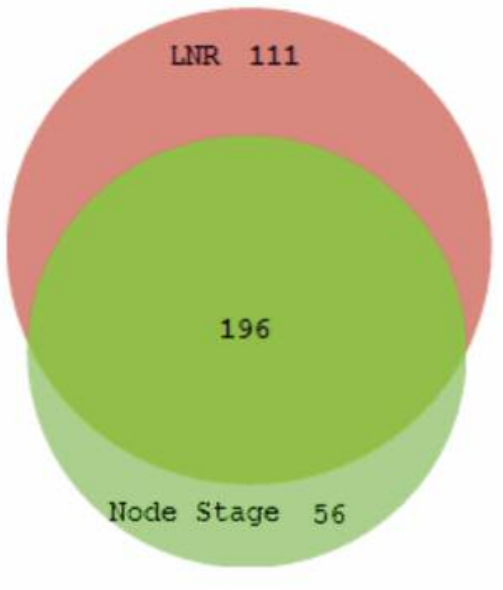

Intermediate -risk

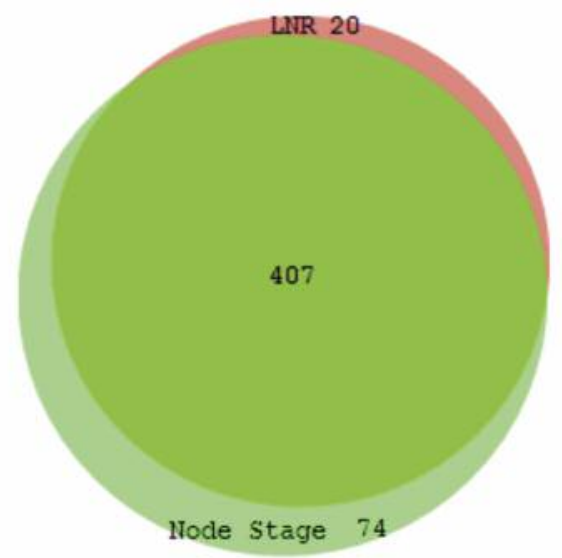

Low-risk

Figure 3. Venn diagrams to illustrate the patients in different risk group by lymph node ratio (LNR), including low-risk, intermediate-risk and highrisk groups corresponding to $\mathrm{N}$ staging including $\mathrm{N1}, \mathrm{N} 2$ and $\mathrm{N} 3$.

Tumor characteristics and molecular subtype were the two most important factors for selecting adjuvant treatment $(19$, 43). The pathological staging system categorizes tumors according to the number of lymph nodes involved: 1-3, 4-9 and 10 or more as N1, N2 and N3, respectively. Some studies have indicated that adding LNR classification to $\mathrm{pN}$ staging is more effective at distinguishing prognoses between lowrisk and high-risk groups. Our results showed that patients in the low-risk group had significantly better survival than patients in the intermediate and high-risk groups. Therefore, studies focused on LNR have considered treatments involving the total resection of the LNs in an attempt to provide more information relating to tumor recurrence, which was in agreement with the primary hypothesis.

Among the highly proliferative/high- ER-sensitive tumors, relapses occurring after 5 years of adjuvant tamoxifen treatment are the most common, although risk of recurrence is modest during the first 5 years of tamoxifen treatment (44). Although several predictive markers have been identified, no factor that precisely predicts long-term survival 
A

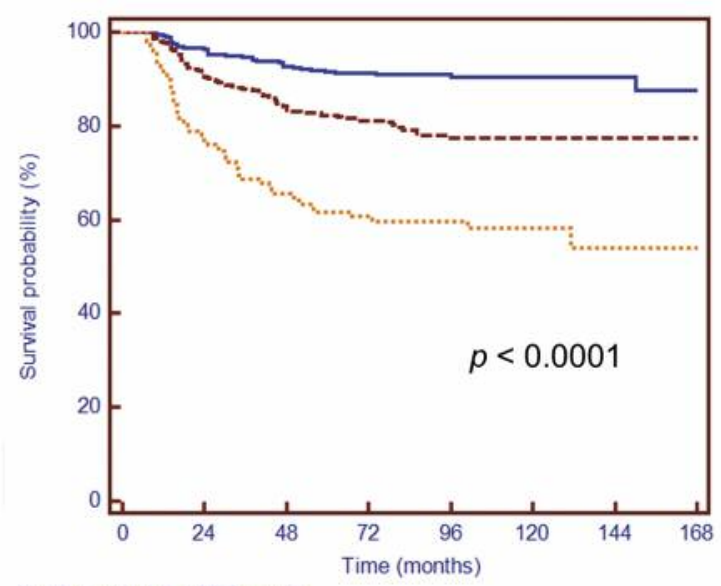

Number at risk for DFS events Low-risk

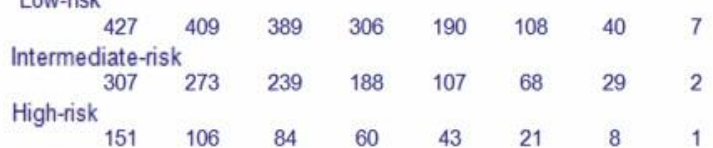

C

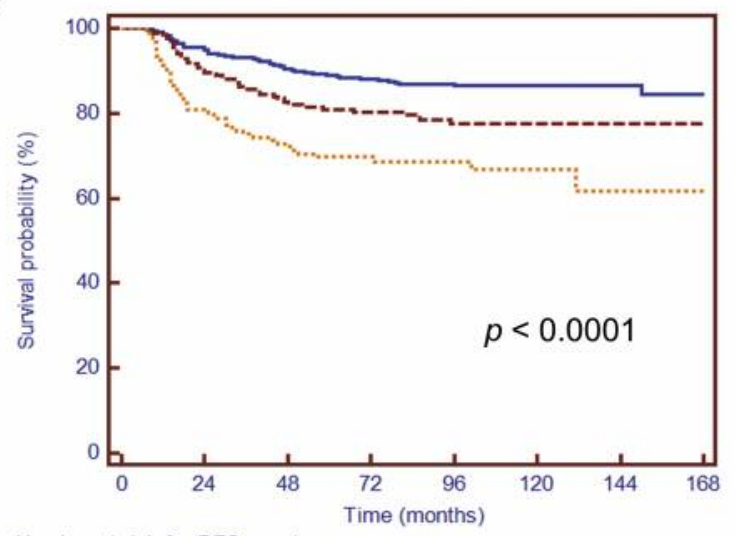

Number at risk for DFS events Low-risk

\begin{tabular}{|c|c|c|c|c|c|c|}
\hline 481 & 455 & 428 & 339 & 210 & 127 & 50 \\
\hline Intermediate- & & & & & & \\
\hline 252 & 222 & 192 & 146 & 86 & 49 & 19 \\
\hline High-risk & & & & & & \\
\hline 152 & 111 & 92 & 69 & 44 & 21 & 8 \\
\hline
\end{tabular}

B

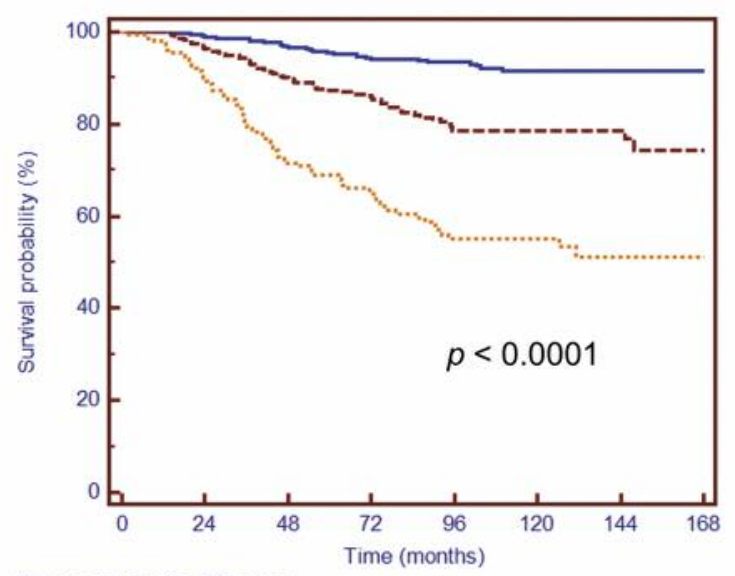

Number at risk for OS events Low-risk

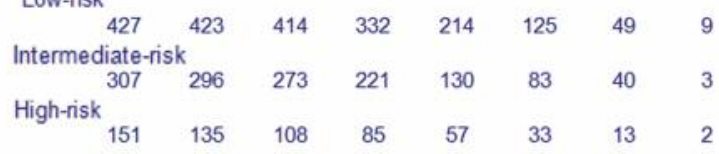

D

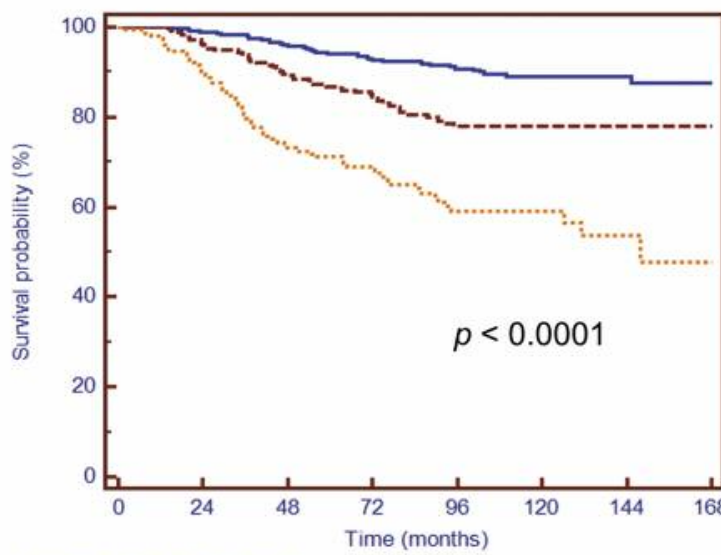

Number at risk for OS events

Low-risk

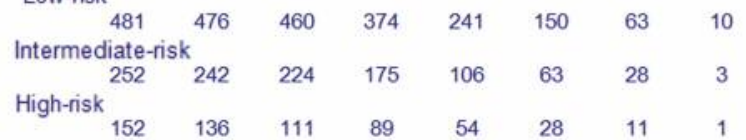

Figure 4. Analyses of disease-free $(A, C)$ and overall $(B, D)$ survival according to different lymph node ratio $(L N R)$ cut-off values. A-B, Lower and upper values: $A, B: 0.20$ and $0.63 ; C, D: 0.20$ and 0.65 .

in breast cancer patients has been reported. In a recent study in Lancet Oncology, patients with luminal-A subtype tumors were recommended to receive 10 years of endocrine therapy (45). All of the patients enrolled in these studies were recommended to receive 5 years of endocrine therapy rather than 10 years. Thus, we could not determine the effect of LNR in patients who received long-term endocrine therapy. However, our results here showed that LNR as a continuous variable gave a high adjusted HR in both DFS and OS in patients who were administered selective ER modulators. 

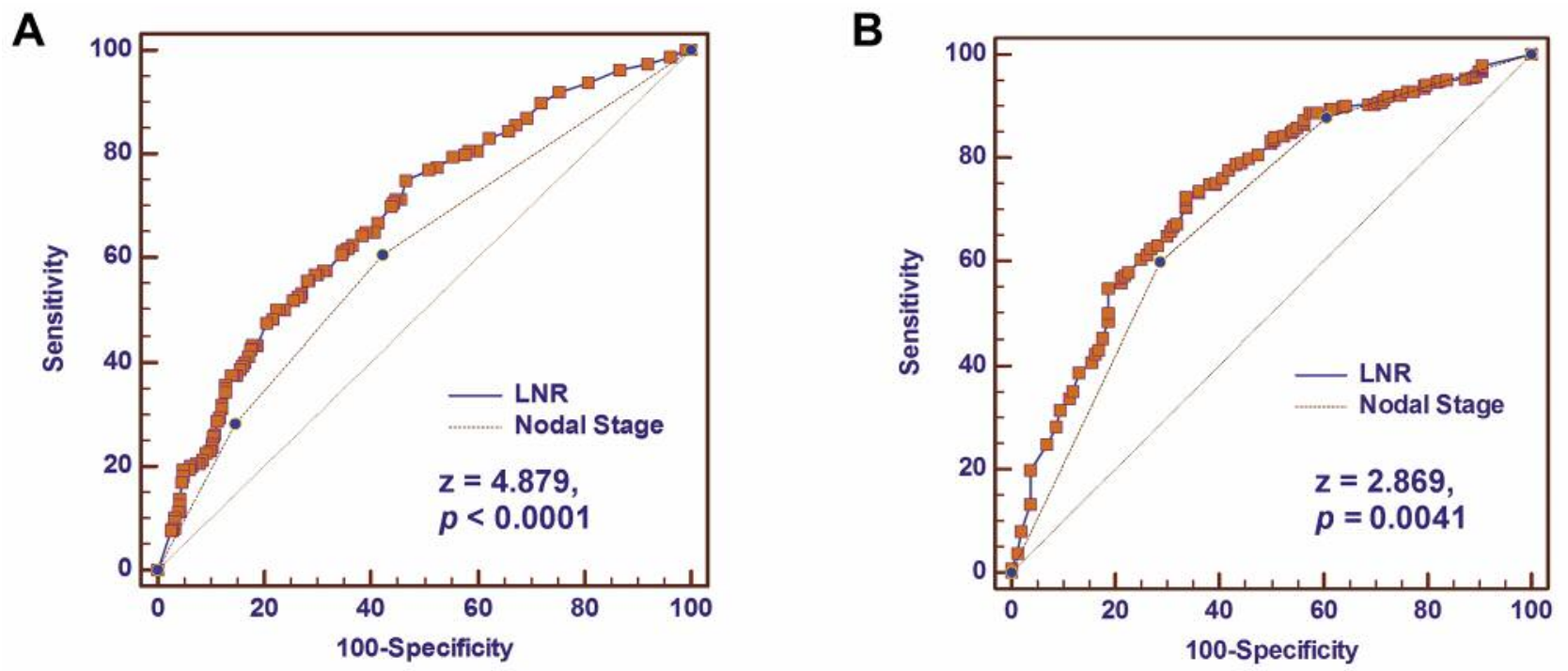

Figure 5. Receiver operating-characteristic curves comparing the use of lymph node ratio (LNR) and N staging to predict disease-free (DFS) (A) and overall $(O S)$ survival events $(B)$.

Specifically, patients in the high- and intermediate-risk groups were more than 5- and 2-fold more likely, respectively, to experience disease recurrence than patients in the low-risk group.

LNR is an alternative prognostic factor to $\mathrm{pN}$ staging for lymph node-positive breast cancer $(39,46)$. Accumulating evidence has supported the prognostic value of LNR in breast cancer (39, 46-49). Receiver operating-characteristic curve analysis showed that the AUC of LNR was slightly higher than the AUC of $\mathrm{pN}$ staging. In addition, nomogram analysis showed that LNR contributed more than any other factor to predicting both breast cancer recurrence and mortality. However, the optimal cut-off value remains unclear. In early studies, LNR cut-off values to evaluate risk for breast cancer was not definite $(48,50-52)$. The high-risk group had a significantly increased risk of breast cancer recurrence and metastases in patients with lymph node-positive breast cancer. Several studies subsequently indicated that patients can be categorized into low- $(\leq 0.20)$, intermediate- $(>0.20$ and $\leq 0.65)$, and high-risk $(>0.65)$ groups by LNR. These results demonstrated that patients in the high-risk group had significantly lower DFS than patients in the intermediate- and low-risk groups (53-55). However, there were also some studies that used 0.25 and 0.55 (54) or 0.10 and 0.65 (57) for the high- and low-risk groups, respectively. In our study, we used X-tile to categorize patients into low-, intermediate- and high-risk groups by using lower cut-off values for the LNR lower (0.20) and upper (0.63) cut-offs. Patients in the highrisk group had significantly worse prognoses than patients in the intermediate- and low-risk groups.
LNR was used to assist in determining whether adjuvant radiotherapy should be used in N1-3 patients. Although the tumor recurrence rate was reduced in patients using endocrine therapy, patients inevitably acquired resistance to these therapies $(58,59)$. Several effective drugs, including fulvestrant, aromatase inhibitors, and the CDK4/6 inhibitor palbociclib, have been approved to treat luminal subtype breast cancer that selective estrogen receptor modulators have failed to treat effectively (60-63). Therefore, screening for biomarkers that can be used to predict breast cancer recurrence after breast surgery is important. Significant progress has been made in understanding the molecular biomarkers of breast cancer, and axillary lymph node status remains one of the fundamental prognostic factors that guides the decision to undergo post-mastectomy radiation therapy.

There are some limitations to this study. Its conclusions are based on a single-center study that incorporated a large breast cancer sample size. Secondly, information was not available for all of the patients regarding early tumor grade and Ki-67 index scores because not all tumor samples had been tested. Thirdly, the drugs used included toremifene, which is not commonly used in premenopausal patients with breast cancer as an endocrine therapy. However, we have confirmed that there was no difference in DFS between patients receiving toremifene and tamoxifen treatment for premenopausal breast cancer (64).

In conclusion, we determined that LNR is significantly associated with poor prognosis in lumina-subtype premenopausal breast cancer. Further research is required to 


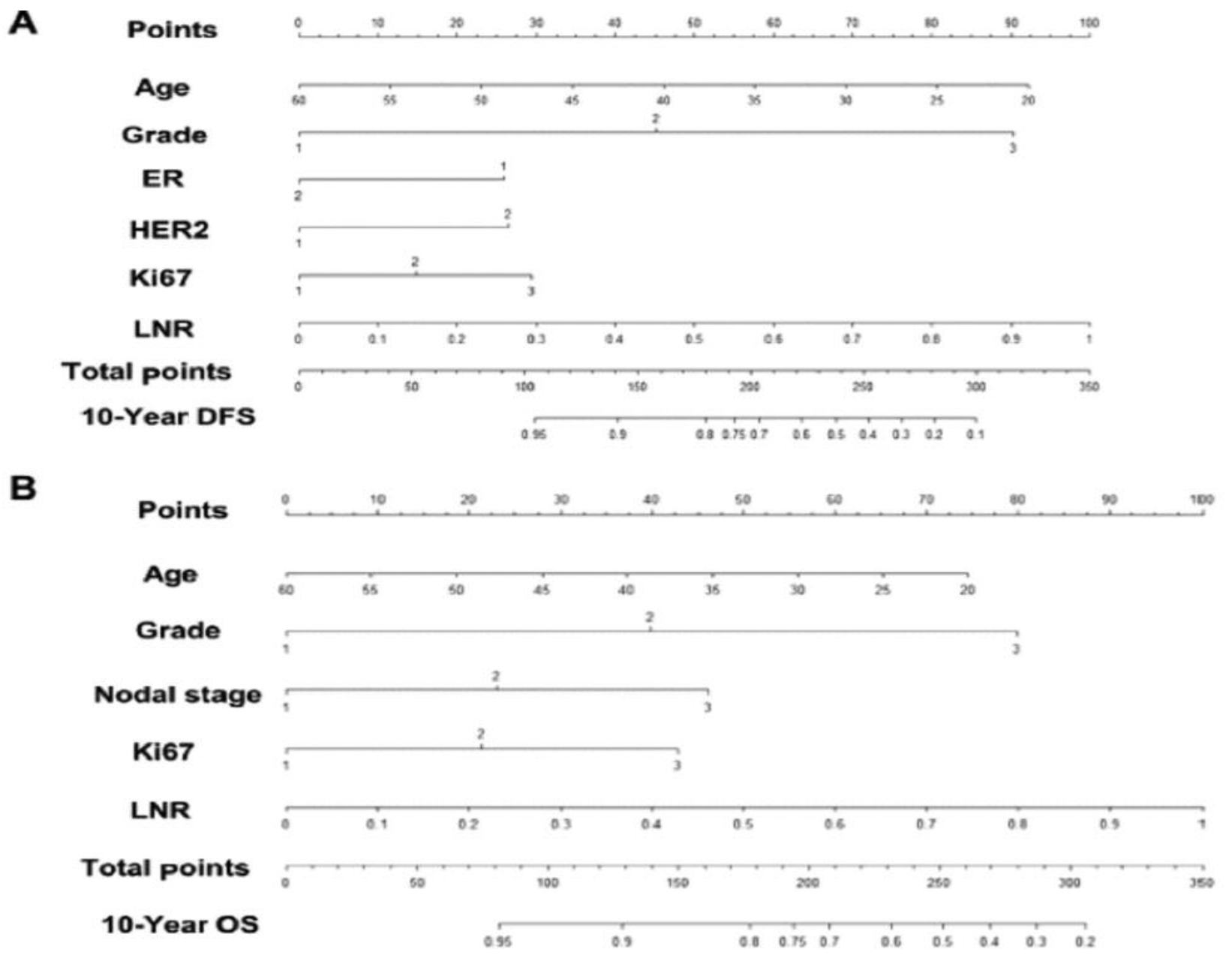

Figure 6. Nomogram to predict the probability of survival: 10-year disease-free survival (DFS) (A) and overall survival (OS) (B), respectively, using grade (1, grade I; 2, grade II; 3, grade III), nodal stage ( $1, N 1 ; 2, N 2 ; 3, N 3)$, estrogen receptor (ER:1, negative; 2, positive), human epidermal growth factor receptor-2 (HER2: 1, negative; 2,positive), and Ki67 (1, $\leq 14 \% ; 2,>14 \% ; 3$, unknown), lymph node ratio (LNR) and age.

determine whether a particular cut-off value for LNR can be used to predict tumor recurrence or breast cancer survival.

\section{Conflicts of Interest}

The Authors declare no conflicts of interest in regard to this study.

\section{Acknowledgements}

This study was supported by a grants from the Science and Technology Planning Project of Guangdong Province China (2014A020212384), the National Natural Science Foundation of China (81502302), the Medical Scientific Research Foundation of Guangdong Province, China (A2017092). The Authors acknowledge the China Scholarship Council.

\section{References}

1 Chen W, Zheng R, Zeng $\mathrm{H}$ and Zhang S: The updated incidences and mortalities of major cancers in China, 2011. Chin J Cancer 34: 502-507, 2015.

2 Torre LA, Bray F, Siegel RL, Ferlay J, Lortet-Tieulent J and Jemal A: Global cancer statistics, 2012. CA Cancer J Clin 65: 87-108, 2015.

3 Curtis C, Shah SP, Chin SF, Turashvili G, Rueda OM, Dunning MJ, Speed D, Lynch AG, Samarajiwa S, Yuan Y, Graf S, Ha G, Haffari G, Bashashati A, Russell R, McKinney S, Group M, Langerod A, Green A, Provenzano E, Wishart G, Pinder S, Watson P, Markowetz F, Murphy L, Ellis I, Purushotham A, Borresen-Dale AL, Brenton JD, Tavare S, Caldas C and Aparicio $\mathrm{S}$ : The genomic and transcriptomic architecture of 2,000 breast tumours reveals novel subgroups. Nature 486: 346-352, 2012. 
4 Perou CM, Sorlie T, Eisen MB, van de Rijn M, Jeffrey SS, Rees CA, Pollack JR, Ross DT, Johnsen H, Akslen LA, Fluge O, Pergamenschikov A, Williams C, Zhu SX, Lonning PE, Borresen-Dale AL, Brown PO and Botstein D: Molecular portraits of human breast tumours. Nature 406: 747-752, 2000.

5 Liu J, Chen K, Mao K, Su F, Liu Q and Jacobs LK: The prognostic value of age for invasive lobular breast cancer depending on estrogen receptor and progesterone receptor-defined subtypes: A NCDB analysis. Oncotarget 7: 6063-6073, 2016.

6 Peng R, Wang S, Shi Y, Liu D, Teng X, Qin T, Zeng Y and Yuan $Z$ : Patients 35 years old or younger with operable breast cancer are more at risk for relapse and survival: a retrospective matched case-control study. Breast 20: 568-573, 2011.

7 Si W, Li Y, Han Y, Zhang F, Wang Y, Li Y, Linghu RX, Zhang $\mathrm{X}$ and Yang J: Epidemiological and clinicopathological trends of breast cancer in Chinese patients during 1993 to 2013: a retrospective study. Medicine 94: e820, 2015.

8 Early Breast Cancer Trialists' Collaborative Group, Davies C, Godwin J, Gray R, Clarke M, Cutter D, Darby S, McGale P, Pan HC, Taylor C, Wang YC, Dowsett M, Ingle J and Peto R: Relevance of breast cancer hormone receptors and other factors to the efficacy of adjuvant tamoxifen: patient-level meta-analysis of randomised trials. Lancet 378: 771-784, 2011.

9 Fan Y, Ding X, Xu B, Ma F, Yuan P, Wang J, Zhang P, Li Q and Luo Y: Prognostic significance of single progesterone receptor positivity: a comparison study of estrogen receptor negative/progesterone receptor positive/HER2 negative primary breast cancer with triple-negative breast cancer. Medicine 94 : e2066, 2015.

10 Early Breast Cancer Trialists' Collaborative Group: Effects of chemotherapy and hormonal therapy for early breast cancer on recurrence and 15-year survival: an overview of the randomised trials. Lancet 365: 1687-1717, 2005.

11 Bao $\mathrm{T}$ and Davidson NE: Adjuvant endocrine therapy for premenopausal women with early breast cancer. Breast Cancer Res 9: 115, 2007.

12 Goldhirsch A, Wood WC, Gelber RD, Coates AS, Thurlimann B, Senn HJ and th St. Gallen c: Progress and promise: highlights of the international expert consensus on the primary therapy of early breast cancer 2007. Ann Oncol 18: 1133-1144, 2007.

13 Bernhard J, Luo W, Ribi K, Colleoni M, Burstein HJ, Tondini C, Pinotti G, Spazzapan S, Ruhstaller T, Puglisi F, Pavesi L, Parmar V, Regan MM, Pagani O, Fleming GF, Francis PA, Price KN, Coates AS, Gelber RD, Goldhirsch A and Walley BA: Patientreported outcomes with adjuvant exemestane versus tamoxifen in premenopausal women with early breast cancer undergoing ovarian suppression (TEXT and SOFT): a combined analysis of two phase 3 randomised trials. Lancet Oncol 16: 848-858, 2015.

14 Pagani O, Regan MM, Walley BA, Fleming GF, Colleoni M, Lang I, Gomez HL, Tondini C, Burstein HJ, Perez EA, Ciruelos E, Stearns V, Bonnefoi HR, Martino S, Geyer CE, Jr., Pinotti G, Puglisi F, Crivellari D, Ruhstaller T, Winer EP, Rabaglio-Poretti M, Maibach R, Ruepp B, Giobbie-Hurder A, Price KN, Bernhard J, Luo W, Ribi K, Viale G, Coates AS, Gelber RD, Goldhirsch A, Francis PA, Text, Investigators S and International Breast Cancer Study G: Adjuvant exemestane with ovarian suppression in premenopausal breast cancer. N Engl J Med 371: 107-118, 2014.

15 Davies C, Pan H, Godwin J, Gray R, Arriagada R, Raina V, Abraham M, Medeiros Alencar VH, Badran A, Bonfill X,
Bradbury J, Clarke M, Collins R, Davis SR, Delmestri A, Forbes JF, Haddad P, Hou MF, Inbar M, Khaled H, Kielanowska J, Kwan WH, Mathew BS, Mittra I, Muller B, Nicolucci A, Peralta O, Pernas F, Petruzelka L, Pienkowski T, Radhika R, Rajan B, Rubach MT, Tort S, Urrutia G, Valentini M, Wang Y, Peto R and Adjuvant Tamoxifen: Longer Against Shorter Collaborative Group: Long-term effects of continuing adjuvant tamoxifen to 10 years versus stopping at 5 years after diagnosis of oestrogen receptor-positive breast cancer: ATLAS, a randomised trial. Lancet 381: 805-816, 2013.

16 Jatoi I anderson WF, Jeong JH and Redmond CK: Breast cancer adjuvant therapy: time to consider its time-dependent effects. J Clin Oncol 29: 2301-2304, 2011.

17 Leggett LE, Lorenzetti DL, Noseworthy T, Tiwana S, Mackean $\mathrm{G}$ and Clement $\mathrm{F}$ : Experiences and attitudes toward risk of recurrence testing in women with breast cancer: a systematic review. Breast Cancer Res Treat 144: 457-465, 2014.

18 Goldhirsch A, Ingle JN, Gelber RD, Coates AS, Thurlimann B, Senn HJ and Panel m: Thresholds for therapies: highlights of the St Gallen International Expert Consensus on the Primary Therapy of Early Breast Cancer 2009. Ann Oncol 20: 1319-1329, 2009.

19 Goldhirsch A, Winer EP, Coates AS, Gelber RD, Piccart-Gebhart M, Thurlimann B, Senn HJ and Panel Members: Personalizing the treatment of women with early breast cancer: highlights of the St Gallen International Expert Consensus on the Primary Therapy of Early Breast Cancer 2013. Ann Oncol 24: 2206-2223, 2013.

20 Dowsett M, Sestak I, Lopez-Knowles E, Sidhu K, Dunbier AK, Cowens JW, Ferree S, Storhoff J, Schaper C and Cuzick J: Comparison of PAM50 risk of recurrence score with oncotype DX and IHC4 for predicting risk of distant recurrence after endocrine therapy. J Clin Oncol 31: 2783-2790, 2013.

21 Sgroi DC, Sestak I, Cuzick J, Zhang Y, Schnabel CA, Schroeder B, Erlander MG, Dunbier A, Sidhu K, Lopez-Knowles E, Goss $\mathrm{PE}$ and Dowsett M: Prediction of late distant recurrence in patients with oestrogen-receptor-positive breast cancer: a prospective comparison of the breast-cancer index (BCI) assay, 21-gene recurrence score and IHC4 in the TransATAC study population. Lancet Oncol 14: 1067-1076, 2013.

22 Sgroi DC, Carney E, Zarrella E, Steffel L, Binns SN, Finkelstein DM, Szymonifka J, Bhan AK, Shepherd LE, Zhang Y, Schnabel CA, Erlander MG, Ingle JN, Porter P, Muss HB, Pritchard KI, Tu D, Rimm DL and Goss PE: Prediction of late disease recurrence and extended adjuvant letrozole benefit by the HOXB13/IL17BR biomarker. J Natl Cancer Inst 105: 10361042, 2013.

23 Ligibel JA, Cirrincione CT, Liu M, Citron M, Ingle JN, Gradishar W, Martino S, Sikov W, Michaelson R, Mardis E, Perou CM, Ellis M, Winer E, Hudis CA, Berry D and Barry WT: Body mass index, PAM50 subtype and outcomes in nodepositive breast cancer: CALGB 9741 (Alliance). J Natl Cancer Inst 107(9): djv179, 2015.

24 Chen CC, Lin JC and Chen KW: Lymph node ratio as a prognostic factor in head and neck cancer patients. Radiat Oncol 10: $181,2015$.

$25 \mathrm{He} \mathrm{Z}$, Wu S, Li Q, Lin Q and Xu J: Use of the metastatic lymph node ratio to evaluate the prognosis of esophageal cancer patients with node metastasis following radical esophagectomy. PLoS One 8: e73446, 2013.

26 Kinnier CV, Paruch JL, Dahlke AR, Wayne JD, Benson AB, 3rd, Winchester DP and Bilimoria KY: Adjusted hospital sentinel 
lymph node positivity rates in melanoma: a novel potential measure of quality. Ann Surg 263: 392-398, 2016.

27 Lee CC, Ho HC, Su YC, Lee MS, Hung SK and Chen YL: The prognostic ability of log odds of positive lymph nodes in oral cavity squamous cell carcinoma. Medicine 94: e1069, 2015

28 Sun G, Xue L, Wang M and Zhao X: Lymph node ratio is a prognostic factor for non-small cell lung cancer. Oncotarget 6 : 33912-33918, 2015.

29 Chen S, Liu Y, Huang L, Chen CM, Wu J and Shao ZM: Lymph node counts and ratio in axillary dissections following neoadjuvant chemotherapy for breast cancer: a better alternative to traditional pN staging. Ann Surg Oncol 21: 42-50, 2014.

30 Rosa Mendoza ES, Moreno E and Caguioa PB: Predictors of early distant metastasis in women with breast cancer. J Cancer Res Clin Oncol 139: 645-652, 2013.

31 Wu SG, Chen Y, Sun JY, Li FY, Lin Q, Lin HX and He ZY: Using the lymph nodal ratio to predict the risk of locoregional recurrence in lymph node-positive breast cancer patients treated with mastectomy without radiation therapy. Radiat Oncol 8: 119, 2013 .

32 Gradishar WJ anderson BO, Balassanian R, Blair SL, Burstein HJ, Cyr A, Elias AD, Farrar WB, Forero A, Giordano SH, Goetz M, Goldstein LJ, Hudis CA, Isakoff SJ, Marcom PK, Mayer IA, McCormick B, Moran M, Patel SA, Pierce LJ, Reed EC, Salerno KE, Schwartzberg LS, Smith KL, Smith ML, Soliman H, Somlo G, Telli M, Ward JH, Shead DA and Kumar R: Breast Cancer Version 2.2015. J Natl Compr Canc Netw 13: 448-475, 2015.

33 Zhang YN, Zhou YD, Mao F and Sun Q: Impact of the 21-Gene Recurrence Score Assay in adjuvant chemotherapy selection for node-negative, hormone receptor-positive breast cancer in the Chinese population. Neoplasma 62: 658-665, 2015.

34 Kondo M, Hoshi SL, Yamanaka T, Ishiguro H and Toi M: Economic evaluation of the 21-gene signature (Oncotype DX) in lymph node-negative/positive, hormone receptor-positive early-stage breast cancer based on Japanese validation study (JBCRG-TR03). Breast Cancer Res Treat 127: 739-749, 2011.

35 Smyth L, Watson G, Walsh EM, Kelly CM, Keane M, Kennedy MJ, Grogan L, Hennessy BT, O'Reilly S, Coate LE, O'Connor M, Quinn C, Verleger K, Schoeman O, O'Reilly S and Walshe JM: Economic impact of 21-gene recurrence score testing on early-stage breast cancer in Ireland. Breast Cancer Res Treat 153: 573-582, 2015.

36 Edge S B, Compton C C: The American Joint Committee on Cancer: the 7th edition of the AJCC cancer staging manual and the future of TNM. Ann Surg Oncol 17(6): 1471-1474, 2010.

37 Lakhani SR, Ellis IO, Schnitt SJ, Tan PH, van de Vijver MJ eds: World Health Organisation Classification of Tumours of the Breast, Fourth Edition. Lyon, France: IARC Press, 2012.

38 Camp RL, Dolled-Filhart M and Rimm DL: X-tile: a new bioinformatics tool for biomarker assessment and outcome-based cut-point optimization. Clin Cancer Res 10: 7252-7259, 2004

39 Vinh-Hung V, Verkooijen HM, Fioretta G, Neyroud-Caspar I, Rapiti E, Vlastos G, Deglise C, Usel M, Lutz JM and Bouchardy $\mathrm{C}$ : Lymph node ratio as an alternative to $\mathrm{pN}$ staging in nodepositive breast cancer. J Clin Oncol 27: 1062-1068, 2009.

40 Lim E, Metzger-Filho O and Winer EP: The natural history of hormone receptor-positive breast cancer. Oncology 26: 688-694, 696, 2012.

41 Rakha EA and Ellis IO: Lobular breast carcinoma and its variants. Semin Diagn Pathol 27: 49-61, 2010.
42 Ciriello G, Gatza ML, Beck AH, Wilkerson MD, Rhie SK, Pastore A, Zhang H, McLellan M, Yau C, Kandoth C, Bowlby R, Shen H, Hayat S, Fieldhouse R, Lester SC, Tse GM, Factor RE, Collins LC, Allison KH, Chen YY, Jensen K, Johnson NB, Oesterreich S, Mills GB, Cherniack AD, Robertson G, Benz C, Sander C, Laird PW, Hoadley KA, King TA, Network TR and Perou CM: Comprehensive molecular portraits of invasive lobular breast cancer. Cell 163: 506-519, 2015.

43 Coates AS, Winer EP, Goldhirsch A, Gelber RD, Gnant M, Piccart-Gebhart M, Thurlimann B, Senn HJ and Panel M: Tailoring therapies--improving the management of early breast cancer: St Gallen International Expert Consensus on the Primary Therapy of Early Breast Cancer 2015. Ann Oncol 26: 15331546, 2015 .

44 Bianchini G, Pusztai L, Karn T, Iwamoto T, Rody A, Kelly C, Muller V, Schmidt S, Qi Y, Holtrich U, Becker S, Santarpia L, Fasolo A, Del Conte G, Zambetti M, Sotiriou C, Haibe-Kains B, Symmans WF and Gianni L: Proliferation and estrogen signaling can distinguish patients at risk for early versus late relapse among estrogen receptor positive breast cancers. Breast Cancer Res 15: R86, 2013.

45 Burstein HJ, Temin S anderson H, Buchholz TA, Davidson NE, Gelmon KE, Giordano SH, Hudis CA, Rowden D, Solky AJ, Stearns V, Winer EP and Griggs JJ: Adjuvant endocrine therapy for women with hormone receptor-positive breast cancer: American Society of Clinical Oncology Clinical Practice Guideline focused update. J Clin Oncol 32: 2255-2269, 2014.

46 Wang F, He W, Qiu H, Wang X, Guo G, Chen X, Rong Y, Zhou $\mathrm{F}$, Yin $\mathrm{C}$, Yuan $\mathrm{Z}$ and $\mathrm{Xia} \mathrm{L}$ : Lymph node ratio and $\mathrm{pN}$ staging show different superiority as prognostic predictors depending on the number of lymph nodes dissected in Chinese patients with luminal A breast cancer. Clin Breast Cancer 12: 404-411, 2012.

47 Chang YJ, Chung KP, Chen LJ and Chang YJ: Recursive partitioning analysis of lymph node ratio in breast cancer patients. Medicine 94: e208, 2015.

48 Dings PJ, Elferink MA, Strobbe LJ and de Wilt JH: The prognostic value of lymph node ratio in node-positive breast cancer: a Dutch nationwide population-based study. Ann Surg Oncol 20: 2607-2614, 2013.

49 van der Wal BC, Butzelaar RM, van der Meij S and Boermeester MA: Axillary lymph node ratio and total number of removed lymph nodes: predictors of survival in stage I and II breast cancer. Eur J Surg Oncol 28: 481-489, 2002.

50 Kim SI, Cho SH, Lee JS, Moon HG, Noh WC, Youn HJ, Ko BK and Park BW: Clinical relevance of lymph node ratio in breast cancer patients with one to three positive lymph nodes. Br J Cancer 109: 1165-1171, 2013.

51 Yang C, Liu F, Li S, Li W, Zhai L, Ren M, Li Y, Lang R, Fan Y, Zhang $\mathrm{X}$ and $\mathrm{Fu}$ L: Lymph node ratio: a new feature for defining risk category of node-positive breast cancer patients. Int J Surg Pathol 20: 546-554, 2012.

52 Bolwell B andresen S, Pohlman B, Sobecks R, Goormastic M, Rybicki L, Bell K and Kalaycio M: Prognostic importance of the axillary lymph node ratio in autologous transplantation for highrisk stage II/III breast cancer. Bone Marrow Transplant 27: 843846, 2001.

53 Ahn SH, Kim HJ, Lee JW, Gong GY, Noh DY, Yang JH, Jung SS and Park HY: Lymph node ratio and $\mathrm{pN}$ staging in patients with node-positive breast cancer: a report from the Korean breast cancer society. Breast Cancer Res Treat 130: 507-515, 2011. 
54 Chagpar AB, Camp RL and Rimm DL: Lymph node ratio should be considered for incorporation into staging for breast cancer. Ann Surg Oncol 18: 3143-3148, 2011.

55 Danko ME, Bennett KM, Zhai J, Marks JR and Olson JA Jr.: Improved staging in node-positive breast cancer patients using lymph node ratio: results in 1,788 patients with long-term follow-up. J Am Coll Surg 210: 797-805e791, 805-797, 2010.

56 Kim JY, Ryu MR, Choi BO, Park WC, Oh SJ, Won JM and Chung SM: The prognostic significance of the lymph node ratio in axillary lymph node positive breast cancer. J Breast Cancer 14: 204-212, 2011.

57 Li Y, Holmes E, Shah K, Albuquerque K, Szpaderska A and Ersahin C: The prognostic value of lymph node cross-sectional cancer area in node-positive breast cancer: a comparison with $\mathrm{N}$ stage and lymph node ratio. Patholog Res Int 2012: 161964, 2012.

58 Roop RP and Ma CX: Endocrine resistance in breast cancer: molecular pathways and rational development of targeted therapies. Future Oncol 8: 273-292, 2012.

59 Sutherland RL: Endocrine resistance in breast cancer: new roles for ErbB3 and ErbB4. Breast Cancer Res 13: 106, 2011.

60 Beaver JA, Amiri-Kordestani L, Charlab R, Chen W, Palmby T, Tilley A, Zirkelbach JF, Yu J, Liu Q, Zhao L, Crich J, Chen XH, Hughes M, Bloomquist E, Tang S, Sridhara R, Kluetz PG, Kim G, Ibrahim A, Pazdur R and Cortazar P: FDA Approval: Palbociclib for the treatment of postmenopausal patients with estrogen receptor-positive, HER2-negative metastatic breast cancer. Clin Cancer Res 21: 4760-4766, 2015.
61 Burstein HJ, Cirrincione CT, Barry WT, Chew HK, Tolaney SM, Lake DE, Ma C, Blackwell KL, Winer EP and Hudis CA: Endocrine therapy with or without inhibition of epidermal growth factor receptor and human epidermal growth factor receptor 2: a randomized, double-blind, placebo-controlled phase III trial of fulvestrant with or without lapatinib for postmenopausal women with hormone receptor-positive advanced breast cancer-CALGB 40302 (Alliance). J Clin Oncol 32: 3959-3966, 2014.

62 Harding E: Palbociclib for hormone receptor-positive breast cancer. Lancet Oncol 16: e318, 2015.

63 Howell SJ: Advances in the treatment of luminal breast cancer. Curr Opin Obstet Gynecol 25: 49-54, 2013.

64 Qin T, Yuan ZY, Peng RJ, Zeng YD, Shi YX, Teng XY, Liu DG, Bai B and Wang SS: Efficacy and tolerability of toremifene and tamoxifen therapy in premenopausal patients with operable breast cancer: a retrospective analysis. Curr Oncol 20: 196-204, 2013.
Received May 12, 2017

Revised June 9, 2017

Accepted June 16, 2017 